\title{
¿Qué es la neorruralidad? \\ Reflexiones sobre la construcción de un objeto multidimensional
}

What is Neo-Rurality? Reflections on the Construction of a Multidimensional Object

O que é a neo-ruralidade? Reflexões sobre a construção de um objeto multidimensional

Luciana Geraldine Trimano*

Recibido: 5 de julio de 2018

Aprobado: 11 de enero de 2019

Doi: http://dx.doi.org/10.12804/revistas.urosario.edu.co/territorios/a.6951

Para citar este artículo:

Trimano, L. (2019). ¿Qué es la neorruralidad? Reflexiones sobre la construcción de un objeto multidimensional. Territorios, (41), 119-142. Doi: http://dx.doi.org/10.12804/revistas.urosario.edu.co/territorios/a.6951

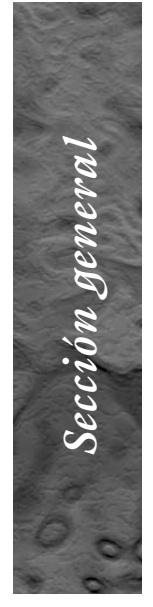

\footnotetext{
* Doctora en Comunicación Social por la Facultad de Ciencias de la Comunicación de la Universidad Nacional de Córdoba (Argentina). Investigadora Asistente del Consejo Nacional de Investigaciones Cientificas y Técnicas (Conicet) en el Centro de Investigaciones y Estudios sobre Cultura y Sociedad (CIECS), Universidad Nacional de Córdoba (UNC) (Argentina). Correo electrónico: lucianatrimano@conicet.gov.ar ORCID: https://orcid.org/00000002-5634-8175
} 
Palabras clave

Neorruralidad, rural, urbano, teoría, metodología.

Keywords

Neo-rurality, rural, urban, theory, methodology.

Palavras-chave

Neo-ruralidade, rural, urbano, teoria metodologia.

\section{territarias 41}

\section{RESUMEN}

Este trabajo discute la noción de neorruralidad como herramienta analítica con la intención de esbozar una propuesta conceptual que colabore en enriquecer el conocimiento científico sobre esta temática. El objeto neorruralidad, si bien ha sido trabajado especialmente en Europa todavía es poco explorado en Latinoamérica. Esta situación provoca una notable ausencia teóricometodológica al considerar la importancia del contexto en estas investigaciones. Por tal motivo, buscamos problematizar los desafíos analíticos y empíricos que la movilidad ciudad-campo presenta para las ciencias sociales y para aquellos estudios que trabajan esta realidad desde una mirada particular (comunicación, migraciones y movilidades). El análisis parte de la hipótesis de que la noción de neorruralidad es un pseudoconcepto que engaña definiendo un fenómeno que en realidad es más complejo de lo que sugiere la etiqueta, además de prolongar el dualismo ruralurbano. En suma, esta manera de tipificar el fenómeno nos empuja en dirección de un objeto mal construido. Ante este panorama, a partir de un caso de base etnográfica se reflexiona sobre la naturaleza del conocimiento neorrural y sus fuentes, en un ejercicio de indagación en torno a un fenómeno histórico, complejo, emergente, dinámico, situado, localizado, multidimensional (temporal, espacial, espiritual y experiencial) y transdisciplinar.

\section{ABSTRACT}

This article explores the concept of neo-rurality as an analytical tool, aiming to create a conceptual proposal that collaborates with the development of the study of this social phenomenon. Even though the neo-rurality object has been analysed particularly in Europe, it is underexplored in Latin America. This situation generates a remarkable theoretical-methodological absence when considering the importance of context in this research. For this reason, we aim at problematizing and reshaping the analytical and empirical challenges that the city-countryside movement represents for social sciences in general and for those studies that address this reality from a particular point of view (communication, migration, and movement). The analysis arises from the assumption that the concept of neo-rurality is a misleading pseudo-concept since it defines a phenomenon that is, in fact, more complex than what the label suggests and widens the rural-urban dualism. In summary, this way of typifying the phenomenon pushes us towards a wrongly-built object. Given this scenario, on the basis of an ethnographic case, this essay reflects on the nature of the neo-rural knowledge and its sources, inquiring about a complex, emerging, dynamic, situated, identified, multidimensional (temporal, spatial and experiential) and transdisciplinary historical phenomenon.

\section{RESUMO}

Este trabalho discute a noção de Neo-ruralidade como ferramenta analítica, com a intenção de esboçar uma proposta conceitual que colabore em enriquecer o conhecimento científico sobre esta temática. O objeto neo-ruralidade, embora tem sido trabalhado especialmente na Europa, ainda é pouco explorado na Latino-América. Esta situação provoca uma notável ausência teórico-metodológica ao considerar a importância do contexto nestas pesquisas. Por este motivo, buscamos problematizar os desafios analíticos e empíricos que a mobilidade cidade-campo 
apresenta para as ciências sociais e para aqueles estudos que trabalham esta realidade desde um olhar particular (comunicação, migrações e mobilidades). A análise parte da hipótese de que a noção de neo-ruralidade é um pseudo-conceito que engana definindo um fenômeno que, em realidade, é mais complexo do que sugere a etiqueta; para além de prolongar o dualismo rural urbano. Em suma, esta maneira de tipificar o fenômeno empurra-nos em direção de um objeto mal construído. Ante este panorama, a partir de um caso de base etnográfica, se reflete sobre a natureza do conhecimento neo-rural e suas fontes, em um exercício de indagação em torno a um fenômeno histórico, complexo, emergente, dinâmico, situado, localizado multidimensional (temporal, espacial, espiritual e experiencial) e transdisciplinar.

\section{Introducción}

A lo largo del siglo $\mathrm{xx}$, y especialmente desde los años setenta, toma fuerza un flujo de movilidad que se dirige de la ciudad al medio rural ${ }^{1}$. La opción de vivir en contacto con la naturaleza se convierte en un sueño perseguido, en un ideal para algunos citadinos que se instalan en pequeñas aglomeraciones con un proyecto de vida alternativo al vertiginoso mundo de las urbes. Este movimiento, denominado por la academia neorruralidad ${ }^{2}$, adquiere formas diversas y genera transformaciones en las sociedades receptoras. En paralelo, la irrupción y propagación de nuevos patrones de consumo y hábitos de vida, la extensión de las metrópolis, las comunicaciones y la creciente movilidad de la población modifican los patrones de organización del territorio y reconfiguran las estructuras económicas y sociales de las localidades (Capel, 2009).

La neorruralidad aparece así como una tendencia emergente de movilidad ${ }^{3}$ poblacional y residencial gestada al calor de una sociedad contemporánea que busca una manera de habitar el mundo diferente a la estipulada en el régimen semiótico del capitalismo. Es un desplazamiento humano que brega por desandar las huellas de la modernidad en los imaginarios y en las experiencias cotidianas, en la que lo vital prima sobre lo económico (Trimano, 2015; 2017).

El análisis de la movilidad residencial invita a explorar experiencias y maneras de concebir y percibir las pequeñas aglomeraciones por parte de actores situados: aquellos "inmigrantes-urbanos" que buscan proyectos fundados en el reencantamiento de la naturaleza (Trimano, 2014) y los otros, "lugareños-rurales", que reciben este flujo poblacional. De esta interacción entre grupos con trayectorias y experiencias diversas surgen transformaciones espaciales, temporales, relacionales e identitarias.

Los estudios sobre la neorruralidad, como sucede en un campo en exploración, no presentan uniformidad de criterios, varían según las particularidades espacio-temporales y de la disciplina que los trabaje. Es así que si bien el fenómeno
${ }^{1}$ Desde los años setenta, los núcleos centrales de las áreas metropolitanas dejaron de atraer - por primeravez en la historia - efectivos poblacionales y comenzaron un lento declive en el numero de sus habitantes, mientras que sus periferias residenciales crecieron a ritmo constante. A su vez, otras áreas urbanas no metropolitanas, núcleos urbanos de menor tamaño $y$ áreas rurales distantes, iniciaron un substancial crecimiento demográfico basado esencialmente en los desplazamientos definitivos de población (Arroyo, 2001 en de Abrantes, 2017).

${ }^{2}$ En este trabajo nos desmarcamos de la noción de neorruralidad para señalar, justamente, que uno de los objetivos es abrir la caja negra de lo neorrural. Además, remplazamos la denominación comunidad rural con circunloquios como pequeñas comunidades periféricas y similares debido a que lo rural está en discusión.

${ }^{3}$ La realidad se observa desde el paradigma de las "movilidades" (Urry, 2007) y no desde los estudios de las "migraciones" ya que los censos argentinos no recuperan los movimientos poblacionales que se despliegan dentro de las fronteras de una misma provincia.

territarias 41

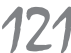


${ }^{4}$ En la etnografía se cobra conciencia del lado subjetivo de los procesos y se reconoce la presencia del investigador en la realidad local: sus interpretaciones, sensaciones, angustias (Rockwell, 2009).

5 Si bien forma parte del corredor turístico cordobés, es uno de los pueblos serranos menos afectado por la masificación de esta actividad. Además, habita gran cantidad de población nacida y criada en el lugar.

"A través de la técnica "bola de nieve" (Valles, 1999) conformamos una muestra intencional de jóvenes $y$ adultos nativos e inmigrantes residentes en la localidad desde 1940. La "teoria fundamentada" (Glaser \& Strauss, 1967) determinó el número de entrevistas. Utilizamos técnicas de investigación directa (trabajo etnográfico, entrevistas no estructuradas $y$ observación) y documental (censos nacionales de población desde 1947 hasta 2010).

\section{territarias 41}

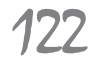

ha sido estudiado en profundidad principalmente en Europa, se aborda de manera incipiente en los países latinoamericanos, particularmente en la Argentina, donde la mayoría de trabajos sobre migración interna históricamente se han abocado a las corrientes migratorias rural-urbano (Rodríguez \& Busso, 2009).

La identidad nacional Argentina se construye y se afirma en la creencia de que es fruto del "crisol de razas" (Grimson, 2011). La inmigración de ultramar es cardinal en la edificación de la cultura nacional (Devoto, 2007). Así, desde finales del siglo XIX, nuestro país ha estado asociado al fenómeno migratorio y por ello existe una larga trayectoria de trabajos que lo han examinado como una "respuesta forzosa" a condiciones sociales y económicas. Sin embargo, son escasos los estudios en los que la migración interna se considera producto de "atracciones positivas" (Nakayama \& Marioni, 2007; González, Otero, Nakayama \& Marioni, 2009) y pertenecen en especial a la geografía humanista (González, 2003).

El carácter prematuro de las movilidades de la ciudad al medio rural y su condición situada no ha permitido hasta el momento configurar una agenda de investigación. Para dar luz a la problemática, presentamos, a modo de referente empírico, un caso de base etnográfica ${ }^{4}$ correspondiente a la localidad de Las Ca$\mathrm{lles}^{5}$, en el valle de Traslasierra, Córdoba, Argentina, donde es posible percibir una movilidad residencial citadina que desde hace veinte años, toma fuerza de forma cualitativa y cuantitativa.

Este trabajo apunta a comprender el modo en que los actores experimentan el sentido de su vida, su cotidianeidad, sus hechos extraordinarios y su devenir (Guber, 2005). Por ello, los datos y conclusiones son producto del análisis de los testimonios de personas que se han radicado en la pequeña aglomeración, así como también del de aquellos que los reciben. Las elecciones residenciales de los protagonistas y sus impactos en la identidad comunal son la base de este estudio ${ }^{6}$.

El trabajo empírico pone de manifiesto que aquellas localidades atadas a marcos teóricos sobre lo "rural" se transforman. El espacio en el que interactúan las personas se reconfigura debido al impacto de un repertorio de prácticas y representaciones "urbanas". Este acontecer muestra que algunos conceptos pierden sus componentes o adquieren otros en situaciones diferentes; esto exige repensar las nociones con las que nombramos el mundo experiencial.

El caso de estudio es ideal para analizar cómo cada vez más un amplio número de citadinos, oriundos de grandes ciudades, comienzan a habitar pequeñas comunas y a interactuar, no sin tensiones, con la sociedad de acogida. El planteamiento pretende ser un contrapunto al momento de situar las experiencias de movilidad y las transformaciones que estas producen en los habitantes y sus territorios, también es un ejercicio de vigilancia epistemológica para estudiar presentes fluctuantes. 
El concepto de neorruralidad plantea dificultades - e incomodidades - al investigador que se propone analizarlo. Cuestiones tales como ‘a quién entrevistar? ¿Qué tipo de prácticas observar? O ¿qué dimensiones contemplar? requieren una determinación previa de los límites y alcances de lo que se observa y comprende con dicha noción.

Este trabajo reflexiona sobre la naturaleza del conocimiento neorrural y sus fuentes, e invita a sumergirse en un ejercicio de indagación en torno a un fenómeno histórico ${ }^{7}$, emergente $^{8}$, complejo $^{9}$, dinámico, situado ${ }^{10}$, localizado, multidimensional (temporal, espacial, espiritual y experiencial) y transdisciplinar.

Partimos de la premisa de que los estudios neorrurales, al haber sido desarrollados en especial por la geografía, se han dedicado a explorar básicamente la dimensión espacial: el traslado de un grupo urbano hacia el campo y la consecuente extinción de territorios tradicionales rurales o comunidades orgánicas como expresión de estas dinámicas. No obstante, la escasa incursión de otras miradas disciplinarias en el análisis del objeto ha descuidado los impactos y las reconfiguraciones en términos relacionales e identitarios.

Para reconocer cómo se especifica la neorruralidad desde la perspectiva del encuentro entre actores y territorio adoptamos un enfoque multidimensional y accedemos a las transformaciones a partir de experiencias. Esta manera de exponer los límites conceptuales y empíricos pretende hacer justicia en la construcción de un objeto, que es a la vez un flujo y una conexión atravesado por el prisma de lo temporal, lo espacial, lo introspectivoespiritual y lo experiencial. Trabajar estos procesos conjuntamente involucra una gran cantidad de dimensiones que exigen la búsqueda de diversas herramientas de análisis. Además, permite replantearse una serie de nociones troncales para las ciencias sociales: naturaleza, sociedad, territorio, comunidad, identidad y cultura.

El desafío que enfrentamos es el de sostener la especificidad de un objeto cuya lógica propia es la del movimiento. Por eso, esclarecer de qué hablamos cuando hablamos de la neorruralidad es hacer emerger aspectos diversos y múltiples. En las páginas que siguen revisamos los antecedentes de la noción de neorruralidad para dar soporte teórico a la discusión. A continuación, presentamos las características de la ruralidad serrana para situar el caso, comprender las dinámicas locales y desde ahí fundamentar empíricamente el trabajo. En un tercer momento, utilizamos como clave de lectura el caso etnográfico para pasar a explorar las dimensiones que postulamos que atraviesan y dan cuerpo a este fenómeno. Una vez especificados los aspectos que organizan la inteligibilidad del objeto, esbozamos una propuesta conceptual acerca de la neorruralidad a modo de hipótesis disparadora.
7 Referirse a las condiciones politicas y sociales permite detectar sentidos y consecuencias conforme a la coyuntura de su aparición.

${ }^{8}$ La emergencia se produce en el intersticio: lo que emerge no es lo nuevo, es la constitución de elementos que se ocupan de un devenir, al mismo tiempo que son contradictorios entre si dentro de una contemporaneidad (Foucault, 1994).

${ }^{9}$ El pensamiento complejo desarrollado por Edgar Morin (transdisciplinariedad) es actualmente un asidero epistemológico que ayuda a comprender fenómenos inéditos.

${ }^{10}$ Es el reconocimiento de la intersubjetividad que supone la investigación con "otros", entendida como un proceso dialógico, abierto $y$ contingente y no como la captura de un otro extraño. Habilita a rebasar la idea representalista del objeto para asumir la propiedad relacional de todos los elementos que lo constituyen - simbióticos, semióticosmateriales y politicos entre sujeto-investigador y objeto- (Haraway, 1997)

\section{tersitorias 41}

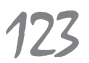


${ }^{11}$ Las tipologías neorrurales o estrategias sociorresidenciales varian según la distancia física que el medio rural elegido tenga con la ciudad: ya sea como una consecuencia del desarrollo del capitalismo (movimiento pendular-barrios cerrados - instrumentalización de la naturaleza) o como la emergencia de un fenómeno de ruptura (corte abrupto con la vida urbana).

12 Convertidos en una leyenda con el paso de los años, los diggers -que tomaron su nombre de un grupo de campesinos ingleses del siglo XVII que se reapropiaron de tierras baldías con la idea de "que los ricos trabajen solos por su lado y que los pobres lo hagan juntos por el suyo"surgen en el icónico barrio de Haight-Ashbury en San Francisco (California, Estados Unidos) en 1966 y duran hasta 1968 en medio de la indolencia del hippismo. Es un movimiento radicalmente subversivo, anticapitalista $y$ artístico que decretó la "muerte del dinero" bajo la consigna: "iTodo es gratis porque es nuestro!". Pusieron en práctica un comunismo arcádico, dirigian un almacén gratuito y tenian una cadena de albergues gratuitos para itinerantes (Hall, 1970).

\section{territarias 41}

\section{De la ciudad al campo. Antecedentes teóricos}

Existe gran diversidad de posiciones ante el objeto de estudio: neorruralidad ${ }^{11}$. Sus orígenes se remontan a los trabajos sobre migración interna realizados por el geógrafo estadounidense Edward Ullman ( 1954 en Moss, 2006) y se profundizan en 1970 de la mano del también geógrafo norteamericano Brian Berry (1976), propulsor de la noción de contraurbanización. Para estos estudios, la búsqueda de una mejor calidad de vida era el motivo principal que impulsaba las decisiones migratorias desde grandes ciudades hacia áreas rurales o pequeños centros urbanos. Ambos, con matices, describían la misma tendencia: el deseo de la población de estar cerca de la naturaleza, la libertad de movimiento y la aspiración de mantener la individualidad en pequeños grupos homogéneos (Champion, 1989). Sofranko y Williams (1980) entendieron las razones de este cambio detectando tipos de inmigrantes rurales: aquellos que desean mejorar su condición económica y los que pretenden una mejor calidad de vida. Por su parte, en la misma década, investigadores franceses estudiaron el éxodo de personas que se estaban instalando en el medio rural como vía de escape a los efectos sociales que estaba produciendo la economía capitalista. Bertrand Hervieu y Danièle Léger (1977) sostuvieron que ante la crisis, la contaminación y la burocracia de la vida cotidiana, "los inmigrantes de la utopía" recurren a la naturaleza, a un mundo rural magnificado por su imaginación, símbolo de armonía, de solidaridad y de comunidad. Los valores característicos del mundo rural de antaño que se creían en vías de extinción rebrotan, son reinventados por gente de la ciudad que ahora no se traslada hacia el campo por falta de trabajo (Giuliani, 1990), sino en busca de "algo" que no encuentran en la urbe.

Estos movimientos poblacionales tienen sus antecedentes en dos momentos históricos: por un lado, el Mayo Francés. Por otro, la contracultura de los años sesenta y el underground estadounidense, cuyo episodio más interesante es el movimiento de los diggers $^{12}$, en un contexto en el que, aunque brevemente, sectores de la juventud de este país intentaron vivir de una forma distinta a la que el American way of life, entonces en su apogeo, proponía al resto de la humanidad como modelo de civilización (Gaillard, 2010).

En la misma época, Argentina recibe esta influencia, que tiene su réplica en versiones neorrurales pioneras. Muestra de ello es la migración hippie a la comarca de El Bolsón en la Patagonia Andina y la constitución de un segundo asentamiento de estas características en el municipio de San Marcos Sierras, en la provincia de Córdoba. Sin embargo, en estas latitudes los estudios comienzan en 1990 (Leveau, $2009)^{13}$, cuando en los centros turísticos comienza a sentirse el impacto de la especulación inmobiliaria (Lacarrieu \& Thuiller, 2001; Ciccolella, 2007) en la dinámica poblacional y el sistema económico local. 
Los orígenes del fenómeno, entonces, datan de 1960 y 1970, aunque podríamos ir más atrás si consideramos que este proceso de reencuentro con la naturaleza y la comunidad ya había sido analizado por Henry Thoreau (2013) y Ferdinand Tönnies (2009). Si bien el fenómeno no es nuevo en la historia de la humanidad, recién comienza a ser nombrado con el término neorruralidad en 1981 por $\mathrm{Mi}$ chel Chevalier para hacer referencia a la “instalación en el campo de un colectivo mayoritariamente joven, procedente de las zonas urbanas". A partir de aquí comienza la historia del concepto como lo conocemos en la actualidad, aunque también es el principio de un sinfín de connotaciones diversas que poco ayudan a delimitar el fenómeno.

En este sentido, según las aproximaciones teóricas, el fenómeno neorrural (Léger \& Hervieu, 1977; Chevalier, 1981; Mormont, 1990; Camarero Rioja, 1993; Rivera Escribano, 2007) también suele ser denominado migración de amenidad (Moss, 2006; Nakayama \& Marioni, 2007), contraurbanización (Champion, 1998; Halfacree, 2001; Paniagua, 2002, Ratier, 2002; Erbiti, 2008; Cardoso, 2013), migración por estilo de vida (Benson \& O'Reilly, 2009), migración residencial (Gurran, 2011), naturbanizacion (Prados, 2011) o retorno a la naturaleza (Nates Cruz \& Raymond, 2007).

También es común encontrar análisis en los que la noción de neorruralidad se confunde con la de "nueva ruralidad", acuñada por corrientes de la sociología rural latinoamericana para referirse a las transformaciones del mundo rural contemporáneo debido a la aplicación de políticas neoliberales cristalizadas en el agronegocio transnacional (Giarracca, 2001). Algunos autores argumentan que la migración al campo es parte de los procesos de las "nuevas ruralidades" (Ratier, 2002, 2003; Kay, 2009), aunque con este planteamiento el movimiento de citadinos al medio rural aparece como una experiencia residual y accesoria de otras macrodinámicas.

En virtud de esta complejidad, la mayor parte de la literatura adopta una posición que reserva el concepto de neorrural para designar el traslado de la ciudad al medio rural de individuos que buscan un modo de vida "alternativo" al que proponen las sociedades capitalistas. Así, "son neorrurales todas aquellas personas que abandonan la ciudad y se dirigen al campo con un proyecto de vida alternativo que puede ser tan diverso como diversas son las actividades a realizar" (Nogué, 1988).

Pueden destacarse tres grandes estudios sobre la neorruralidad que coinciden, únicamente, en un aspecto de la teoría: el desarrollo en los territorios de un proceso de dispersión de la población. Desde el urbanismo y la geografía - procedentes de bibliografía española- el interés radica en observar el renacimiento de las áreas rurales y el aumento de su número de habitantes. Se alude a un proceso de desconcentración de población de las áreas metropolitanas y a la aparición de núcleos de población o al crecimiento de otros ya existentes (Arroyo, 2001).
${ }^{13}$ El autor atribuye estos cambios al traslado de un modelo de industrialización sustitutiva de importaciones (concentración demográfica) a otro basado en el crecimiento del sector terciario y rentístico-financiero (desconcentración). tersitarios 41

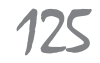


La sociología europea (en España, Francia y Bélgica) considera la neorruralidad como una consecuencia del despoblamiento que se produce en las ciudades, en especial cuando se alude a segundas residencias (Paniagua, 2002; Hall \& Müller, 2004). Irse a vivir al campo es la elección de un proyecto vital, un cambio en el estilo de vida (Mormont, 1990; Camarero Rioja, 1993; Rivera Escribano, 2007). En otra línea, analistas del turismo norteamericano prefieren hablar de migración de amenidad (Moss, 2006) para indagar en las cualidades del ambiente natural de las áreas rurales y analizar los impactos sociales del turismo en la comunidad receptora (Eriksen, 1970 en Nakayama, Marioni, Lonac \& Otero 2005). No obstante, la escasez de datos sobre aspectos socioculturales es una de las principales limitaciones de estos estudios. Exiguas líneas de investigación se interesan por el sentido que adquiere la comunidad como sociedad receptora (Kemmis, 1992; Moss \& Godde, 1999).

En la Argentina particularmente la geografía observa la relación que se establece entre el paisaje y la construcción del sentido del lugar de los sujetos neorrurales (González, 2003). También se hace referencia a la contraurbanización y se la asume como un cambio de tendencia motorizado por factores económicos, políticos, ambientales, demográficos, tecnológicos, urbanísticos y de movilidad (Erbiti, 2008; Cardoso, 2013).

Todavía más, el pasaje de un munterritarias 41 do sedentario/fijo a otro móvil puede rastrease en las reflexiones que aporta la geografía cultural sobre las prácticas de movilidad de viajeros, turistas y migrantes, es decir, sobre los impactos de los nuevos desplazamientos en la configuración de los lugares. Igualmente, estos estudios se preocupan de los espacios rurales como ámbitos de consumo (Zusman, Lois \& Castro, 2007; Castro \& Zusman, 2016; Castro \& Arzeno, 2017; Pérez Winter, 2017).

En el ámbito nacional, también se acercan a la problemática trabajos del campo de la antropología de las moralidades y de una urbana que busca posicionar el abordaje de las ciudades no metropolitanas; estos indican un aumento relativo de la población en ciudades intermedias a partir de la presencia de sectores populares en el espacio público (Noel, 2011, 2014; de Abrantes, 2013; Noel \& de Abrantes, 2014; de Abrantes \& Felice, 2015). Para la agronomía, el colectivo de neorrurales adquiere protagonismo por su trabajo en la implementación de políticas de acceso a la tierra en la agricultura familiar, en el desarrollo local sostenible y en una economía social y solidaria (Barros, 2005; Feito \& Aboitiz, 2013; Novick \& Feito, 2015).

\section{Particularidades del entorno serrano: el caso Las Calles}

La posición céntrica de la provincia de Córdoba en el territorio argentino la convierte en área de contacto de diversas regiones naturales. De modo que sus características topográficas dibujan un ambiente que desde tiempos remotos 
Figura 1. Las Calles

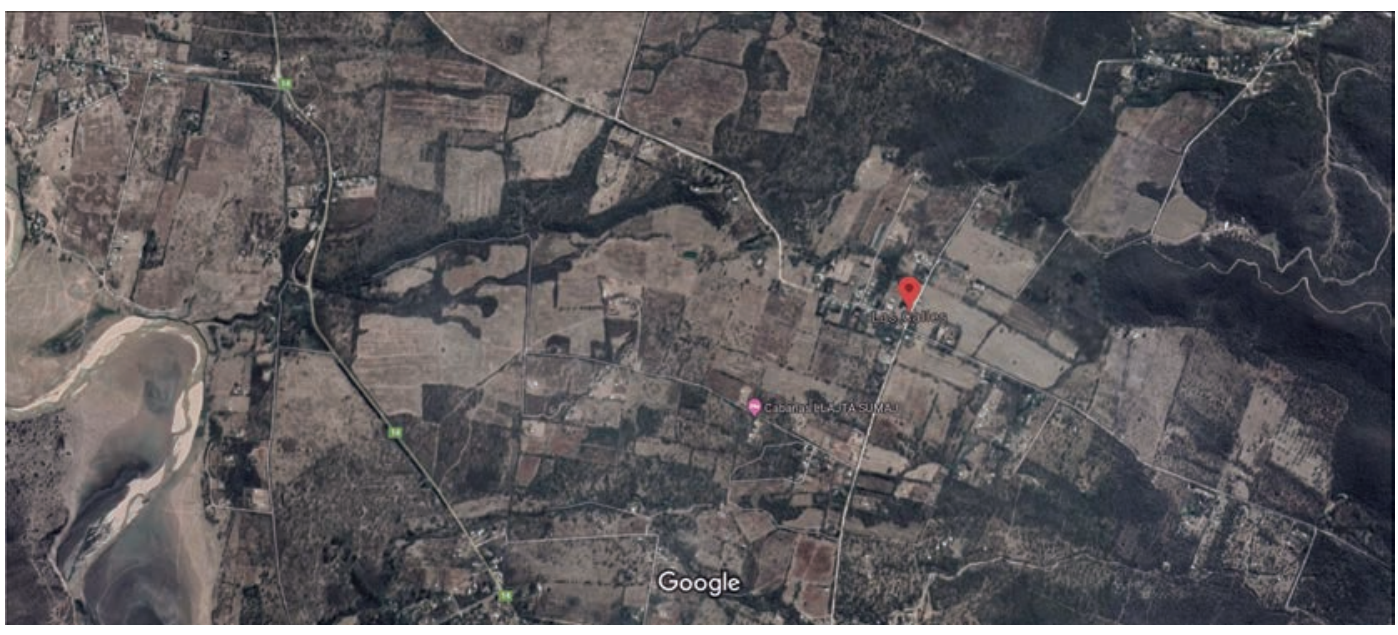

forma parte de una región accesible para la ocupación de grupos culturales que llegan procedentes de diversas rutas de migración (Salinardi, 2006).

En razón de esta ubicación (figura 1), las sierras de Córdoba conforman una ruralidad diferente a la imperante en la Argentina, donde desde las últimas dos décadas predomina el llamado "modelo de agronegocio", cuyo cultivo distintivo es la soja. Un modelo que determina la configuración económica y productiva del país y atraviesa los imaginarios sociales con nociones tales como "desarrollo", "progreso" y "modernidad" (Gras \& Hernández, 2016).

En la región serrana, en cambio, el impacto residencial de citadinos, la expansión demográfica de los pueblos y el crecimiento de la actividad turística provocan una fuerte valoración inmobiliaria

¿QUÉ ES LA NEORRURALIDAD? REFLEXIONES SOBRE LA CONSTRUCCIÓN DE UN OBJETO MULTIDIMENSIONAL
${ }^{14}$ Entre los años 40 y 50 del siglo XX los habitantes se dedicaron al cultivo de tabaco, cría y faena de caprinos y porcinos, fruticultura, recolección y comercialización de hierbas medicinales y aromáticas; así como a la elaboración casera de quesos, embutidos $y$ licores.

de la tierra. Dicho acontecer desplaza, excluye y expulsa a familias y unidades de producción formales e informales típicas de estos territorios, a la par que se evidencian reconfiguraciones morfológicas en el paisaje a partir del cambio de un uso rural a otro urbano, especialmente residencial. En consecuencia, grandes extensiones de suelo productivo pierden su agrodiversidad y el tejido productivo-familiar-rural se transforma ${ }^{14}$.

Los emprendimientos turísticos en expansión no solo impactan la reconfiguración fisonómica de las comunas y los municipios, también reestructuran los mercados laborales: la construcción es la principal fuente de empleo asalariado masculino y el servicio doméstico y la atención al cliente, el femenino. Estas dinámicas afectan de modo desigual a los habitantes originarios según si son propietarios de la

tersitarios 41

127 
${ }^{15}$ El resultado es una zona en tensión: por un lado, el mercado inmobiliario en complicidad con politicos venales buscan beneficios privados de corto plazo - sin responder a un bien común a escala regional-y solo satisfacen las demandas de sectores medio-altos que emigran de la ciudad para fijar residencia o disfrutar la temporada estival; por el otro, una población que se organiza para ejecutar ordenamientos territoriales que promuevan un desarroIlo sostenible.

${ }^{16}$ Desde 1914, los criterios censales argentinos consideran que los entornos rurales son escenarios habitados por menos de 2000 babitantes (Otero, 2007).

17 Las tres ciudades más pobladas de la Argentina y los puntos de mayor concentración de la actividad económica y cultural del pais.

${ }^{18}$ Con excepción de los censos que se realizan cada 10 años, en la Argentina no existe una politica estadistica que recoja datos sistemáticos sobre estas aglomeraciones de menor escala. La Encuesta Permanente de Hogares (EPH), herramienta estadistica que releva los principales indicadores sociales, no se realiza en

\section{tersitarios 41}

tierra, arrendatarios o peones rurales con bajo poder adquisitivo; estos últimos, al igual que sus prácticas, suponen una traba para la extracción de rentas del suelo (Janoschka, 2016) ${ }^{15}$.

A este respecto, en los últimos veinte años, en Traslasierra, uno de los escenarios destacados del corredor turístico argentino - como en otros valles que escapan a este análisis - y particularmente en el pueblo rural ${ }^{16}$ de Las Calles, una localidad de 700 habitantes (Censo Nacional de Población, Hogares y Vivienda 2010) del departamento San Alberto, ha comenzado a registrarse una movilidad que obedece a patrones diferentes a los que venían analizando los estudios de las migraciones, también novedoso para los académicos inscriptos en el "giro de las movilidades" (Zunino, Giucci \& Jirón, 2017).

El nuevo flujo poblacional es protagonizado por personas entre 30 y 60 años de edad, de estratos medios y altos, profesionales en su mayoría, que en algunos casos siendo turistas en estos parajes rurales, deciden retornar para afincarse. De esta forma, un alto porcentaje de inmigrantes, oriundos en general de la metrópoli de Buenos Aires y de ciudades como Córdoba y Rosario ${ }^{17}$, comienzan a insertarse en las comunas y a interactuar, no sin conflictos, con la sociedad receptora.

Una vez instalados, los nuevos habitantes motivan a familiares y amigos a vivir la experiencia del campo y van conformando redes migratorias vehiculizadas por relaciones sociales, cuyo motor es el apoyo personal basado en el parentesco y la amistad. El boca a boca ${ }^{18}$ es el principal canal de información entre los inmigrantes que ya radicados se concentran espacial y simbólicamente en un "círculo iluminado" $(\text { Trimano, 2017) })^{19}$.

Hemos escogido la comuna ${ }^{20}$ de Las Calles como un caso paradigmático a través del cual mirar las experiencias de movilidad residencial y sus impactos. En esta línea, el planteo de Norbert Elias (1998), en su Ensayo teórico sobre las relaciones entre establecidos y marginados, confirma que en pequeñas comunidades con problemáticas aparentemente únicas es posible descubrir "un tema humano universal en miniatura”. En suma, Las Calles es un universo completo donde se traman los factores que analizamos en esta investigación.

En primer lugar, nos permite abonar el supuesto de que la movilidad residencial y los procesos relacionales que proyecta iluminan la emergencia de una zona limina ${ }^{1}$ donde conviven, en interacción, trayectorias y experiencias de personas; donde se solapan temporalidades y espacialidades múltiples, y donde devienen mutaciones identitarias de orden subjetivo, comunal y regional. Las movilidades se hacen cuerpo en los intercambios, suscitan procesos comunicativos, dinamizan redes y activan continuamente encuentros, negociaciones y resistencias entre actores situados.

El segundo motivo de la elección del caso se desprende del primero. Para comprender la sociodinámica de Las Calles, ineludiblemente, las ciencias sociales deben interrogarse sobre la clásica dualidad campo-ciudad. En tercer lugar, Las Calles 
también se fundamenta en que, a pesar de estar ubicada en uno de los circuitos turísticos más destacados del país, todavía no ha sido afectada, en demasía, por la especulación inmobiliaria. Sucede que la ruta provincial 14 - principal arteria vial de movilidad y acceso a la región- no atraviesa el poblado, para ingresar desde la ruta se deben transitar cuatro kilómetros por un camino sin pavimento. En efecto, el transporte público circula con escasa frecuencia. Este aislamiento, como marca material, determina el proceso de urbanización del pueblo y su crecimiento demográfico. Es decir, se constituye en el principal factor por el cual el lugar atraviesa un proceso incipiente y paulatino de transformación social, que merece ser analizado. Al comparar Las Calles con poblaciones aledañas como Mina Clavero y Nono, mejor comunicadas, se observa que estas han recibido mayor impacto de movilidad urbana en los últimos diez años.

Fruto de un proceso de movilidad residencial inverso (de la ciudad al campo), la vida cotidiana de los pueblos de esta región cordobesa transcurre atravesada por un tiempo y un espacio intersticial plagado de divergencias. Aquí, los grupos humanos experimentan la convivencia del tiempo circular de la cosecha y de las temporadas con el tiempo lineal del capitalismo y del progreso (Greene, 2014). En el caso de los nativos, se trata de personas que han visto a sus padres y abuelos valorar el oficio de labrar la tierra y hoy se encuentran cumpliendo horarios de oficina porque la salida laboral inmediata es el servicio de

¿QUÉ ES LA NEORRURALIDAD? REFLEXIONES SOBRE LA CONSTRUCCIÓN DE UN OBJETO MULTIDIMENSIONAL atención al cliente en complejos hoteleros. Es decir, ante la presencia de nuevas subjetividades urbanas, los "lugareños" se ven forzados a reconvertir sus principios generadores y organizadores de prácticas y de representaciones:

Antes, todo el mundo plantaba. Las plantaciones de tabaco eran hermosas, las de frutilla. ¡Uy! Eran tiempos donde teníamos de todo. Ahora la gente ya se cansó. Yo trabajo en este hotel, tengo una jornada de trabajo. Llego a la mañana temprano, me hago el mate y respondo los mails con las reservas; soy la secretaria. Después atiendo a los huéspedes, me gusta el contacto con la gente. Es cansador, llego tarde a mi casa pero me gusta (Lugareña, 35 años).

Ahora vivimos del turismo. Antes toda la gente cosechaba, hacía una quinta, una huerta... Ahora todos esperamos el verano por el turismo. Si no tenés cabañas, alquilas tu casa por temporada (Lugareño, 50 años).

En retrospectiva, Las Calles debe su dinámica actual a las marcas de los procesos agrarios - el tendido del ferrocarril hasta Villa Dolores, la formación de cooperativas y la estructura de la tenencia de la tierra-, pero también al impacto de sucesivos flujos poblacionales sobre el universo simbólico, material, relacional y biosocial de la comunidad.

Así, la herencia de un pasado ligado a la influencia británica $(1947-1970)^{22}$ -donde las relaciones sociales, modeladas bajo la jerarquía y el paternalismo,

dirigida, exclusivamente, a ciudades que superan los 200000 habitantes (de Abrantes, 2017, p. 38). Por ello, una de las dificultades del estudio fue la insuficiencia de datos sobre el proceso de poblamiento de Traslasierra en el periodo reciente.

${ }^{19}$ El análisis sobre la movilidad "gringa" puede encontrase en Trimano (2017).

${ }^{20}$ Asentamiento poblacional de hasta 2000 habitantes (Ley Orgánica $N^{\circ}$ 8102/91 de Municipios de Córdoba). Es comuna desde el año 1992 y pertenece a la antigua pedanía de Nono.

${ }^{21}$ La idea de zona permite delimitar un área (espacio-pueblo-comunaregión-comunidad-sociabilidad-temporalidadexperiencia); no obstante, dichos limites nunca son fijos, pueden desbordarse, desmarcarse y volver a marcarse. La zona liminal es el encuentro fijo/móvil y su resultado una nueva realidad por nombrarse.

${ }^{22}$ El principal evento mencionado por los nativos de Las Calles de la segunda mitad del siglo XX es su actividad laboral en caseríos ingleses y su inscripción como "caseros" (mujeres, en servicio doméstico y varones

\section{territarias 41}

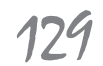


$\Longleftarrow$

en mantenimiento del predio). Este recorte temporal sigue el criterio de relevancia para los propios actores, para quienes esta experiencia colectiva aparece como fundante de la identidad local. Por eso, sin descuidar los verdaderos origenes de esta región (anterior a 1573 el territorio serrano fue habitado por los pueblos originarios Comechingones y Sanavirones), el análisis se reduce al poblamiento de Traslasierra en el periodo bistórico reciente (1940-actualidad). Desde este recorte, postulamos la idea de "nuevos" y "viejos" habitantes, aunque el propósito es problematizar este binomio que determina credenciales de autoctonía. Se interpela a los residentes con un interrogante: ¿quiénes estamos siendo?

23 Expresión autorreferencial utilizada por "nacidos y criados" en Las Calles.

24 Categoria nativa para tipificar a personas foráneas. También se utiliza "venidos de afuera” o "gente de afuera".

25 Construcción nativa para referirse a inmigrantes poseedores de capital económico y cultural, de prolongada trayectoria en el pueblo.

\section{territarias 41} 130 eran de patrón a peón- se imbrica con costumbres tradicionales "criollas". Los pilares ideológicos sobre los que se sustenta la nueva sociedad "callejera" ${ }^{23}$ de fines de los años cuarenta son la honra, la fidelidad, la obediencia y el servicio. Lo expresan los siguientes testimonios:

Aquí llegaron ingleses con dinero, se compraron sus casas y fueron armando su grupo de amigos. Lo bueno es que nos dieron trabajo como 'caseros'. Los ingleses eran buenos (Lugareño, 78 años).

Teníamos una buena relación, la de patrónempleado, claro; uno los tomaba a los ingleses como 'el mayor', en poder adquisitivo y estudios; era 'el señor'. Mi padre decía “esta gente da trabajo” y nos enseñaba a tratarlos con respeto (Lugareña, 31 años).

Esta primera toma de contacto de la sociedad receptora con los nuevos habitantes determinará las formas que guiarán los vínculos con futuras generaciones de inmigrantes, que en este caso particular, trae aparejada una historia de desigualdades y polarización social.

"Lo que sucede" en el pueblo - como espacio de encuentro- es un proceso de atracción y permeabilidad en el contacto entre actores con trayectorias biográficas disímiles. "Lo que irrumpe" es un nuevo modelo de sociabilidad y "la interrupción" de la normalidad serrana se detecta en relaciones identitarias en tensión. "Lo que emerge" son experiencias del encuentro con "otros" próximos exteriorizadas a través de un juego de "etiquetamiento cruzado" - lugareños/forasteros; pueblerinos/citadinos; establecidos/outsiders; nativos/inmigrantes- (Trimano \& de Abrantes, 2017) que despliegan los actores en sus intercambios. El sistema de categorías identitarias creado por los propios nominadores objetiva una modalidad del vínculo existente y es propia del acto de habitar estos territorios y no otros.

A principio de los años ochenta comienza a llegar a Las Calles una nueva corriente de personas oriundas básicamente de Buenos Aires. El movimiento nacional remplaza al europeo. Los "porteños", en su gran mayoría, detentan credenciales económicas y culturales que imprimen prestigio ante la mirada de la sociedad de acogida; rápidamente, los nativos asocian a los "llegados" 24 con los británicos y los bautizan con el mote de "gringos" 25 .

Ahora bien, sucede que a diferencia de los primeros inmigrantes, los "gringos" actuales no brindan las mismas posibilidades laborales a quienes ya estaban en el territorio; aunque sí, como parte de una apuesta socioresidencial, se involucran en la vida política e institucional de la localidad (escuela, comuna y espacios culturales). Los citadinos se exhiben como hacedores de hechos tangibles y virtuosos y en ese mismo acto remarcan la frontera nos/otros. La construcción del arraigo citadino y el porqué de la molestia lugareña se explicita en la cita:

Este pueblo comenzó a crecer cuando llegamos los de la ciudad. Sin descuidar a la

LUCIANA GERALDINE TRIMANO 
gente de acá, obvio, los que venimos de la ciudad tenemos otra energía, más power. Mira, por ejemplo el secundario y la escuela para adultos, ¿quién la hizo? Una gringa. Es un poco así, le damos vida a este pueblo (Inmigrante, 52 años).

Ante el panorama, los primeros habitantes referencian la llegada de "gente de afuera" como un problema:

Se está llenando de 'porteños' 'el valle'. Esta gente piensa que vivir acá es fácil, dicen que quieren estar tranquilos. ¿Sabes qué pasa? Su tranquilidad "invade" la nuestra. Tenemos que alambrar los campos porque se les pasan los animales a su casa; quieren intervenir en la política comunal; te llenan la escuela de duendes. A mí me gustaría vivir como antes, entre nosotros (Lugareña, 45 años).

Así las cosas, Las Calles, quizá por la fama de un conjunto de valores paisajísticos, meteorológicos ${ }^{26}$ y culturales se va convirtiendo en un escenario privilegiado para la recepción de una movilidad urbana que llega con intereses diversos: citadinos en busca de calidad de vida coinciden con inversores inmobiliarios que incentivan la demanda turística. Más aún, la llegada de los nuevos actores confronta con los "nacidos y criados" que se sienten "invadidos".

En la actualidad, los "lugareños" —categoría que desliza la idea de que quienes no son "nacidos y criados" en el pueblo, son "venidos de afuera", "gringos" o "hippies" 27 , es decir, son "invasores" (Trimano, 2017)—desarrollan una identidad política que surge producto de acciones de resistencia para posicionarse como auténticos poseedores del territorio. Una categoría que, como advertimos, tiene sus antecedentes en la historia, en su constitución como sociedad receptora y como "caseros" de "gente que quiere venir acá a imponernos cosas". Esta sensación se lee en los relatos:

La gente de acá no quiere trabajar. Nos cuesta que entiendan que los emprendimientos sustentables están buenísimos (Inmigrante, 60 años).

A los nacidos y criados les encanta 'chupar'. Yo si no tengo plata almuerzo arroz, la gente de acá no piensa igual (Inmigrante, 33 años).

Es difícil compartir con los nativos; ellos tienen mucha desconfianza de los que venimos de la ciudad (Inmigrante, 57 años).

La categoría nativa de invasión permite comprender la estigmatización del forastero, al mismo tiempo que se levanta como una estrategia de la sociedad receptora para preservar su identidad y afirmar una superioridad deseada en resguardo de lo propio. En los relatos lugareños se advierte que prefieren vivir entre sus semejantes antes que en la sociedad heterogénea en la que se van transformando:

A mí me molesta que vino mucha 'gente de afuera' y se creen que el pueblo es como la empresa que manejaban en Buenos Aires,
${ }^{26}$ Las localidades serranas se definen por la emergencia de un turismo saludable y terapéutico. Los primeros habitantes adjudican al microclima de la zona, templado y seco - especialmente recomendado para personas con afecciones respiratorias - la responsabilidad de atraer residentes.

27 Categoría usada por el lugareño como epiteto despectivo para referirse a jóvenes inmigrantes con hábitos de vida "desviados" de la norma. Para el nativo, el hippie es un outsider, un marginal. Un análisis extendido de esta experiencia de movilidad puede encontrase en Trimano (2015).

\section{tersitarios 41}

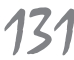


quieren cambiarnos las formas de hacer las cosas. El pueblo es nuestro (Lugareño, 62 años).

Son como una plaga de langostas los de la ciudad; de verdad es una 'invasión' (Lugareña, 68 años).

Lo cierto es que la localidad de estudio hoy es un espacio donde confluyen grupos en tensión; un espacio donde "lugareños" y "venidos de afuera" se excluyen en un "nos/otros" desplegando procesos de alteridad.

La necesidad de los habitantes de identificarse, categorizarse y clasificarse unos con respecto a los otros evidencia una demanda local: preguntarse ¿quiénes somos? (¿Somos un pueblo? ¿Somos una ciudad?). El despliegue de vínculos bajo las formas de un proceso de "etiquetamiento cruzado" advierte sobre la búsqueda de una identidad, que ya no puede actualizarse solo a partir de elementos del pasado, ahora encuentra otras experiencias y se reinventa.

\section{Dimensiones para pensar la neorruralidad y redefinición de la unidad de análisis}

Como se ha visto hasta ahora, repensar el concepto de neorruralidad se plantea como una fase de reflexión y maduración del discurso teórico cimentado en el trabajo empírico.

Se trata de replantear la definición restrictiva de la neorruralidad y dar nueva forma a su abordaje. Por eso, planteamos dos desafíos para estos estudios, uno teórico: ¿cuáles son las dimensiones que conforman y dan cuerpo al fenómeno neorrural? y otro metodológico ‘cómo y desde qué ópticas comprender e interpretar una realidad emergente? Interrogar los tópicos fundacionales facilita la tarea del investigador interesado en entender los mecanismos que accionan y mantienen el fenómeno.

A modo de invitación, proponemos una manera de recortar y analizar un objeto. Elaboramos dimensiones que funcionan como herramientas o como un andamiaje de relevo para mirar la realidad. Es una operación instrumental que pone en entredicho la categoría: neorrural, su primacía y su función fundacional porque sus propiedades no condicen con la experiencia empírica situada que por tanto, no permiten su comprensión. Igualmente, es imposible plantear una propuesta acabada si como advertimos somos conscientes de que lo neorrural opera en el registro de lo fluido y marca el ritmo de un cambio social.

El problema tiene en su base la construcción de una "experiencia" tanto para el sujeto cognoscente como para el objeto conocido. De modo que reflexionamos sobre lo vivido en la neorruralidad, sobre lo cotidiano en su forma transitoria, para captar sus significaciones.

El punto teórico-metodológico actual sobre la neorruralidad podría resumirse en las siguientes premisas. 
La neorruralidad es un fenómeno de reciente análisis para las ciencias sociales y esencialmente las latinoamericanas, lo que provoca una notable ausencia teórica. Su impronta multidimensional y su dinamismo no le permiten encasillarse en esquemas binarios ni marcos disciplinares, por ese motivo no encuentra estatuto epistemológico. La realidad que hoy describe - o hace encajar - la academia dentro de la neorruralidad es estratégica, justamente porque incomoda, porque como un síntoma nos muestra que es imprescindible cambiar el estatuto de lo rural y lo urbano desde el lugar de las transformaciones y el encuentro sociocultural. Es por ello que buscamos nuevas metáforas para visualizar esta otra neorruralidad contemporánea.

Como proceso teórico, el concepto de neorruralismo pertenece a una zona difusa, donde lo rural y lo urbano se encuentran interconectados a partir de la confluencia en un mismo espacio y tiempo de actores con trayectorias y experiencias disímiles. Este entrecruzamiento o esta unión en el intersticio (Trimano, 2014) corporiza otras configuraciones territoriales y experienciales más heterogéneas y conflictivas. Lo que emerge en el intersticio de este encuentro de trayectorias y experiencias rurales y urbanas es una gradualidad: una zona liminal.

La neorruralidad (como fenómeno vivo, no como noción) es lo emergente, es la síntesis de un encuentro que atiende a la excepcionalidad de un estilo de vida rural ya no más contrapuesto a la ciudad, sino fusionado, un juego de espejos latente, una identidad en constante movimiento, construida y reconstruida a partir de interacciones y tensiones entre pares dicotómicos: lugareños/venidos de afuera; pueblerinos/citadinos; establecidos/"invasores"; "paisas" /"gringos".

Así, uno de los mayores problemas al que se enfrenta el fenómeno neorrural es que se reduce al binomio rural-urbano; una dicotomía cuya persistencia en las agendas de investigación de las ciencias sociales viene obstruyendo la posibilidad de comprender escenarios complejos que no se dejan encasillar en los habituales binarismos (Greene, 2014; Noel, 2017).

El objetivo principal es abrir esa "caja negra" de lo neorrural para explorar y problematizar las dimensiones que se ponen en juego en su análisis. Promovemos esta discusión para evitar seguir etiquetando un compartimento estanco donde incluir fenómenos y procesos diversos que refieren simultáneamente a cuestiones distintas. Es necesario recomponer, desde un enfoque transdisciplinar, el impacto que los nuevos desplazamientos humanos producen sobre territorios concretos, modalidades de sociabilidad locales y un conjunto de representaciones y prácticas que tienen en su base las trayectorias biográficas y las experiencias de todos los actores protagonistas del proceso: inmigrantes-urbanos y receptores-rurales. En efecto, este punto es novedoso en el estudio de la neorruralidad porque la noción misma adquiere un sentido diferente al que le viene atribuyendo la academia. Ya no remite solo al estudio de una movilidad urbana, territarias 41

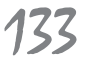


${ }^{28}$ La sintesis que conjuga el hábitat y la esfera cultural implica a los individuos en un todo articulado. Se trata de un desplazamiento "de lo semiótico a lo simbiótico" (Massoni, 2013), en tanto que los objetos naturales son considerados sujetos de derechos.

\section{tersitarias 41}

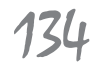

cuyos protagonistas son aquellos que se trasladan, sino al punto de encuentro de actores que establecen fronteras simbólicas y por tanto identitarias.

Tal como quedó planteado en el caso de Las Calles, estudiamos un espacio de frontera entre lo rural y lo urbano, categorías espaciales que se suelen presentar de manera disociada. Por eso, pensar la neorruralidad como una unión intersticial permite saldar, en parte, esas diferencias y cristalizar la emergencia de un fenómeno de ruptura experiencial y teórico.

En consecuencia, ahora la neorruralidad toma otro cariz y puede comprenderse a partir de un registro de conexión; es decir, como un espacio y momento relacionante de la diversidad, que propicia reconfiguraciones espaciales y temporales entre cuerpos vivos en un territorio en particular. El resultado es una trama de relaciones identitarias que interactúan y se tensionan en un entorno biosocial ${ }^{28}$.

De tal manera, la inteligibilidad del objeto neorrural se sustenta en un diálogo entre trayectorias y experiencias, entre ritmos espaciales y temporales, pulsos vitales, prácticas y representaciones que, según hemos constatado a través de los relatos de entrevistados en la etapa exploratoria, divergen: se nutren de imaginarios variados en torno a nociones como desarrollo, progreso, pertenencia, bienestar, trabajo, espacio y tiempo, especialmente, en cuanto a la percepción de quien es el "otro", en un contexto en donde la diversidad de procedencias, pertenencias, tradiciones y valores ponen en juego la configuración de la identidad local.

Pero un estudio sobre la neorruralidad no solo involucra relaciones entre personas (atravesadas por emociones, intereses y preguntas), sino también relaciones con su entorno biosocial. El hábitat determina la forma en que los humanos organizan su experiencia temporal y espacial (ritmos espaciales y temporales) e influye en las sensaciones cuerpo-mente (pulsos vitales). En nuestro caso, el vínculo de los citadinos con las sierras cordobesas es un atributo que se retoma como vía para el reencuentro con lo esencial, con la contemplación, con el hacer y con el arraigo (Trimano, 2017); comparablemente para el "lugareño" el paisaje serrano se presenta como objeto de posesión e identificación.

A partir de aquí nos enfocamos en un proceso que tiene como unidad de análisis las interacciones entre habitantes situados en un territorio particular. Con este propósito, la indagación se organiza en torno a dimensiones heurísticas a fin de desplegar una trama integrada. En virtud de ello, un investigador en terreno puede observar:

- Procesos centrales en torno al territorio como noción y unidad económica (nuevas formas y procesos productivos, nuevas relaciones sociales).

- Los modos de habitar y vivir y la construcción del mundo cotidiano de los actores; la organización del espacio, y el sentido de territorialidad (formas 
en el uso y apropiación de los espacios y la dinámica de reterritorialización).

- La relación entre tiempo y territorio en el sentimiento del arraigo y la construcción de la memoria colectiva, las maneras de concebir el futuro; el significado y las modalidades del trabajo, y la configuración imaginaria de la vida deseable y los valores.

- La definición de identidady alteridad y la representación de los “otros" próximos.

Las dimensiones analíticas permiten cartografiar la diversidad desde la interacción en un contexto donde sabemos se reúnen alianzas, negociaciones y enfrentamientos entre actores. La perspectiva comunicacional posibilita centrase en las articulaciones entre dimensiones (temporales, espaciales, relacionales); esto porque comunicar es traficar con lo que fluye (Massoni, 2016). Así, lo urbano y lo rural coexisten como suturas y disidencias que mutuamente se influencian. En este sentido, el prefijo neo al que se alude para indicar una nueva ruralidad es confuso porque si bien da cuenta de un pasado, no da entidad a lo que sí sucede: una unión en el intersticio.

La propuesta conceptual se orienta a explorar cuáles son las tensiones y mutaciones que los nuevos tipos de desplazamientos humanos generan sobre localidades pequeñas de la Argentina contemporánea. Por ello, la investigación se enfoca en tres transformaciones emergentes propulsadas por las movilidades residencia- les: espaciales, temporales e identitarias. La exploración transdisciplinar (Morin, 1998) es elemental para desmenuzar las reconfiguraciones que se tejen en las cartografías locales.

\section{Propuesta conceptual: redefinición del objeto y sus métodos}

Una vez trazadas las dimensiones heurísticas del objeto, esbozamos de modo inductivo (en diálogo con los datos) una noción. Como todo sistema de clasificación es arbitrario, por ello advertimos que aquí neorruralidad se utiliza como una categoría de la experiencia para pensar espacios de lo posible desde un proceso reflexivo-activo elaborado por los protagonistas. Es un ejercicio complejo empaquetar un fenómeno multidimensional en un concepto, por eso lo exponemos en partes constitutivas.

Para comenzar a definir la neorruralidad debemos reparar en su carácter transitivo, en su liminalidad ${ }^{29}$, tanto en clave teórica para el investigador que estudia esta realidad porosa y elabora neologismos acerca del límite de la frontera entre lo urbano y lo rural como experiencial, para los protagonistas del fenómeno. Es un estado intermedio donde prima la ambigüedad, la hibridez y el cambio.

El momento de transición involucra tres etapas: el traslado de citadinos al medio rural, su génesis, razones y circunstancias; el encuentro con la sociedad receptora, y como corolario la emergencia
${ }^{29}$ Usamos esta noción desarrollada por Arnold van Gennep (1969) y posteriormente por Victor Turner (1980) para objetivar un "proceso transitorio" aunque no es analizado como ritualidad. tersitarios 41

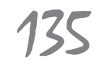


de “otras configuraciones" espaciales, temporales, relacionales e identitarias.

En vista de las partes que componen la neorruralidad postulamos que es una tendencia emergente de movilidad poblacional y residencial motivada por iniciativas vitales estructuradas a partir de "dimensiones introspectivas" (Trimano, 2016), organizadas en torno a la oposición semántica naturaleza-sociedad y su derivado campo-ciudad. Las personas se trasladan desde áreas urbanas, habitualmente grandes ciudades, hacia pequeños asentamientos en áreas rurales. Esta movilidad residencial, como ya dijimos, es protagonizada por jóvenes y adultos que rechazan el modelo urbano de consumo y van conformando un proceso de construcción del arraigo a partir del cuidado de sí, la libertad de movimiento y la creación y el resguardo de una comunidad imaginada.

Una vez instalados en las áreas rurales, los citadinos comienzan a formar parte de la cotidianeidad de las comunidades, que genera relaciones conflictivas con los "lugareños" que se sienten auténticos poseedores de un territorio que, según entienden, forjaron con sus manos. De modo tal, la neorruralidad alude también, por su impacto, a la actitud defensiva de la sociedad receptora, que forja una superioridad deseada para preservar su identidad. Lo emergente, que nace en el intersticio, deviene en encuentros y en tensiones entre "viejos" y "nuevos" habitantes. Es justamente el entrecruzamiento de una diversidad de círculos basados en una sociabilidad entre iguales y los límites que establece la articulación de un "nos/otros", aquello que delimita la identidad local. Esta situación es habilitada por un proceso comunicativo que configura una memoria colectiva fundada en la diversidad.

\section{Reflexiones finales}

En el presente trabajo se analizó la noción restrictiva de neorruralidad, un concepto que la academia viene utilizando para referirse a las migraciones de citadinos hacia el medio rural. El estudio parte de una cierta incomodidad a la hora de comprender, en su completitud, lo que está sucediendo en las poblaciones en estudio. Procuramos hacer frente a una manera, que nos parece insuficiente, de estudiar la neorruralidad y encararla epistemológicamente. Los estudiosos de este campo observan el neorruralismo casi únicamente desde sus condiciones territoriales, siguiendo una mirada estructuralista y de orden cuantitativo. Esta manera de asumir los análisis ha relegado las identidades, las representaciones, los símbolos y las tramas intersubjetivas a un lugar periférico en los estudios académicos, cuando es imposible obviar dichas variables en el entramado neorrural.

¿Cómo indagar las trasformaciones de las pequeñas aglomeraciones si no preguntamos por los ritmos vitales y las trayectorias de los actores que habitan esos territorios? ¿Cómo dar cuenta de espacios y sentidos emergentes si no atendemos a la modalidad del vínculo existente entre 
los actores? ¿Cómo discutimos acerca de espacios heterogéneos y conflictivos si no diseñamos mapas fluidos que den cuenta de relaciones dinámicas? ¿Cómo comprender espacios intersticiales si no sabemos qué componentes los integran? Estas preguntas, fundadas en la dimensión imaginaria de las movilidades, activan el enfoque que pretendemos potenciar.

De este modo, aquellas localidades abandonadas por las ciencias sociales nuevamente las interpelan. Ya no se trata de las migraciones que estábamos acostumbrados a analizar, en todo caso ¿transitamos nuevas formas de desandar el camino de la modernidad? Todo está siendo (ahora) construido en diálogo con los "otros". Estamos obligados a revisar nuestros marcos teóricos y otorgar a la ciencia un carácter situado y móvil, debemos poner en jaque modelos analíticos que ya no cuajan en un mundo experiencial dinámico.

Frente a esta situación, nuestro objetivo fue interrogar la dimensión ontológica del objeto neorrural, donde se engarzan lo urbano y lo rural, para propiciar un debate epistemológico sobre dicha materia y activar disparadores que abran el camino a futuras exploraciones.

Hemos consignado dimensiones heurísticas y aportamos, a modo de hipótesis, una propuesta que nombramos como unión en el intersticio.

Formulamos un enfoque enraizado en los impactos y las transformaciones que este tipo de desplazamientos humanos generan en pequeñas aglomeraciones. El ejercicio fue el de cuestionar la aparente obviedad de un mundo dividido entre "nosotros" y "los otros", mostrando cómo, al desdibujarse las líneas entre el aquí y el allá, el antes y el ahora, el centro y la periferia, lo global y lo local se alteran tanto las certidumbres y fijezas de aquellos que se desplazan, como las de quienes se quedan en sus lugares ancestrales.

Así, llamamos neorruralidad a esa zona liminal donde se produce una unión en el intersticio, resultado de la confluencia de trayectorias y experiencias de actores heterogéneos, que interactúan en un hábitat, al mismo tiempo que son interpelados por él.

El análisis desplegado opera como línea de fuga para entender configuraciones contemporáneas a la hora de hablar del campo y la ciudad en muchas regiones de las sierras de Córdoba, así como en otros territorios de Latinoamérica y del mundo. El desafío es buscar convergencias teóricas y metodológicas para la construcción de sentidos que atiendan el dinamismo de los mundos que habitamos.

\section{Referencias}

Argentina, Insttuto Nacionald de Estadística y Censos (INDEC). (2010). Censo Nacional de Población, Hogares y Viviendas. Argentina: Instituto $\mathrm{Na}-$ cional de Estadística y Censos. Recuperado de http://www.indec.gov.ar/ nivel4_default.asp?id_tema_l=2\&id_ tema_2=41\&id_tema_3 $=135$

Arroyo, M. (2001). La contraurbanización: un debate metodológico y conceptual sobre la dinámica de las áreas metro- territarias 41 


\section{territarias 41}

politanas. Scripta Nova. Revista de Geografía y Ciencias Sociales (97).

Barros, C. (2 de septiembre de 2005). Las caras de la neorruralidad. Agronomía informa. Recuperado de https://www. agro.uba.ar/noticias/node/143

Benson, M., \& O'Reilly, K. (2009). Lifestyl emigration: expectations, aspirations and experiences. Londres: Ashgate.

Berry, B. (1976). Urbanization and counterurbanization. Beverly Hills: Sage.

Camarero Rioja, L. (1993). Deléxodo rural $y$ del éxodo urbano. Ocaso y renacimiento de los asentamientos rurales en España. Madrid: Estudios.

Capel, H. (2009). Las pequeñas ciudades en la urbanización generalizada y ante la crisis global. Investigaciones Geográficas, (70), 7-32.

Cardoso, M. (2013). Contraurbanización en el sistema urbano argentino. El rol de los pueblos grandes en el Área Metropolitana de Santa Fe. En Manual de capacitación docente y a distancia (121128). Santa Fe: Universidad Nacional del Litoral.

Castro, H., \& Zusman, P. (2016). Debates y derivas sobre la ruralidad contemporánea. Reflexiones sobre las políticas de nueva ruralidad desde el campo pampeano. En J. Blanco \& S. Lencioni (Comps.), Argentina e Brasil: territórios em redefinição (281-308). Río de Janeiro: Consequência.

Castro, H., \& Arzeno, M. (2017). Lo rural en definición: aproximaciones y estrategias desde la geografía. Buenos Aires: Biblos.
Champion, A. (1989). Counterurbanization. The changin pace and nature of population deconcentration. Londres: Arnold. Champion, A. (1998). Studying counterurbanization and the rural population turn around. En P. Boyle \& K. Halfacree (Eds.) Migration in to rural áreas. Theories and issues (21-40). Inglaterra: Wiley \& Sons.

Chevalier, M. (1981). Les phénomenes néoruraux. L'Espace Géographique, 1, 3349. Doi: https://doi.org/10.3406/ spgeo.1981.3603

Ciccolella, P. (2007). Territorios del capitalismo global: una nueva agenda para la geografía actual. En M. Fernández (Ed.), Geografía y territorios en transformación (pp. 17-37). Buenos Aires: Noveduc.

de Abrantes, L. (2013). Disputar la ciudad. Apuntes sobre la teoría de la desorganización social. Ponencia presentada en la X Reunión de Antropología del Mercosur, Universidad Nacional de Córdoba.

de Abrantes, L., \& Felice, M. (2015). ¿̨Ciudad sin jóvenes o jóvenes sin ciudad? Reflexiones sobre el derecho a la ciudad en jóvenes que habitan en ciudades intermedias. Cuaderno Urbano, 19 (19), 115-136.

de Abrantes, L. (2017). Habitar entre polos. Una etnografía de las experiencias de transformación urbana en una ciudad media bonaerense. (Tesis de maestría, FLACSO, Argentina).

Devoto, F. (2007). La inmigración de ultramar. En S. Torrado (Comp.), Población

Luciana Geraldine Trimano 
y bienestar en la Argentina del primero al segundo centenario (pp. 531-548). Buenos Aires: Edhasa.

Elias, N. (1998). La civilización de los padres y otros ensayos. Bogotá: Norma.

Erbiti, C. (2008). Un sistema urbano en transformación. Metapolización, metropolización y ciudades intermedias. En J. Roccatagliata (Ed.), Una visión actual y prospectiva desde la dimensión territorial. Buenos Aires: Emecé.

Feito, C., \& Aboitiz, P. (2013). Modalidades de intervención para el desarrollo rural de organizaciones bolivianas: el programa Cambio Rural en Luján. Buenos Aires: INTA.

Foucault, M. (1994). Microfísica del poder. Barcelona: Planeta.

Gaillard, A. (2010). Los diggers. Revolución y contracultura en San Francisco (19661968). España: Pepitas de calabaza.

Giarracca, N. (Comp.) (2001) ¿Una nueva ruralidad en América Latina? Buenos Aires: Clacso.

Giuliani, G. (1990). Neo-ruralismo: o novo estilo dos velhos modelos. Revista Brasileira de Ciências Sociais (14), 59-67.

Glaser, B., \& Strauss, A. (1967). The discover of grounded theory: Strategies for qualitative research. Chicago: Aldine.

González, M. (2003). Una aproximación al paisaje vivencial de neorrurales y otros migrantes en una comarca cordillerana. El caso de El Bolsón en la Patagonia Andina. Revista Geográfica(133), 5-25.

González, R., Otero, A., Nakayama, L., \& Marioni, S. (2009). Las movilidades del turismo y las migraciones de amenidad: problemáticas y contradicciones en el desarrollo de centros turísticos de montaña. Revista de Geografía Norte Grande (44), 75-92. Doi: http://dx.doi.org/10.4067/S071834022009000300004

Gras, C., \& Hernández, V. (2016). Radiografía del nuevo campo argentino. Del terrateniente al empresario transnacional. Buenos Aires: Siglo XXI Editores. Greene, R. (Ed.). (2014). Ciudad Fritanga. Crónicas de ciudades no-metropolitanas. Chile: Bifurcaciones.

Grimson, A. (2011). Los límites de la cultura. Critica de las teorias de la identidad. Buenos Aires: Siglo XXI Editores.

Guber, R. (2005). El salvaje metropolitano. Reconstrucción del conocimiento social en el trabajo de campo. Buenos Aires: Paidós.

Gurran, N. (2011). Migración residencial y transformación social en las costas australianas. En T. Mazón, R. Huete \& A. Mantecón (Eds.), Construir una nueva vida. Los espacios del turismo y la migración residencial (103-128). Santander: Mil razones.

Halfacree, K. (2001). Constructing the object: taxonomic practices, 'counterurbanization' and positioning marginal rural settlement. International Journal Population Geography (7). Doi: https://doi.org/10.1002/ijpg.238

Hall, M., \& Müller, D. (Eds.). (2004). Tourism, mobility and second homes: Between elite landscape and common ground. Clevedon: Channel. territorias 41

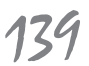

¿QUÉ ES LA NEORRURALIDAD? REFLEXIONES SOBRE LA CONSTRUCCIÓN DE UN OBJETO MULTIDIMENSIONAL 
Hall, S. (1970). Los hippies: una contracultura. Barcelona: Anagrama.

Haraway, D. (1997). Modestwitness@second millennium. Femaleman meets_oncomouse: Feminism and technoscience. New York-London: Routledge.

Janoschka, M. (2016). Gentrificación, desplazamiento, desposesión: procesos urbanos claves en América Latina. Revista INVI, 31(88), 27-71. Doi: http://dx.doi.org/10.4067/S071883582016000300002

Kay, C. (2009). Estudios rurales en América Latina en el período de globalización neoliberal: ¿una nueva ruralidad? $R e-$ vista Mexicana de Sociologia, 71(4), 607-645.

Kemmis, D. (1992). Community and the politics of place. Oklahoma: Norman.

Lacarrieu, M., \& Thuillier, G. (2001). Las urbanizaciones privadas (countries $y$ barrios cerrados) en Buenos Aires. Buenos Aires: Mimeo.

Léger, D., \& Hervieu, B. (1977). Le retour a la nature. París: Seuil.

Leveau, C. (2009). ¿Contraurbanización en Argentina? Una aproximación a varias escalas con base a datos censales del período 1991 y 2001. Boletín del Instituto de Geografía (69).

Massoni, S. (2016). Avatares del comunicador complejo y fluido. Del perfil del comunicador social y otros devenires. Quito: Ciespal.

Morin, E. (1998). Sobre la interdisciplinariedad. Boletin del Centre International

\section{territarias 41} 140
Mormont, M. (1990). Who is rural? or how to be rural?: Towards a sociology of the rural. En T. Marsden, \& P. Lowe (Eds.), Rural Restructuring: global processes and their responses (pp. 21-44). London: Fulton.

Moss, L. (Ed.). (2006). The amenity migrants. Seeking and sustaining mountains and their cultures. UK: CABI.

Moss, L., \& Godde, P. (1999). Strategy for future mountain tourism. En P. Godde, M. Price, \& F. Zimmermann (Eds.), Tourism and development in mountain regions (pp. 323-338). Londres: CABI.

Nakayama, L., \& Marioni, S. (2007). Migración por opción: el fenómeno migratorio en destinos turisticos de montaña. Ponencia prsentada en las IX Jornadas Argentinas de Estudios de Población, Córdoba. Doi: https://doi. org/10.7784/rbtur.vli2.88

Nakayama, L., Marioni, S., Lonac, A., \& Otero, A. (2005). Interacciones y efectos sobre la sustentabilidad del desarrollo local. Caso San Martín de Los Andes y Parque Nacional Lanín. Aportes y Transferencias, 1(9).

Nates Cruz, B., \& Raymond, S. (2007). Buscando la naturaleza. Migración $y$ dinámicas rurales contemporáneas. Barcelona: Anthropos.

Noel, G. (2011). Cuestiones disputadas. Repertorios morales y procesos de delimitación de una comunidad imaginada en la costa atlántica bonaerense. Publicar, (11), 99-126.

Noel, G. (2017). Ni lo uno ni lo otro, sino todo lo contrario. Las limitaciones del

Luciana Geraldine Trimano 
dualismo rural-urbano en el abordaje de la región costera del Río de la Plata y algunas propuestas de reconceptualización. Tessituras, 5(1), 129-170. Doi: http://dx.doi.org/10.15210/ tes.v5il.9991

Noel, G., \& de Abrantes, L. (2014). La gran división. Crecimiento y diferenciación social en una ciudad balnearia de la costa atlántica bonaerense. Argumentos, (16), 141-166.

Nogué i Font, J. (1988). El fenómeno neorrural. Agricultura y Sociedad, (47), 145-175.

Novick, S., \& Feito, C. (2015). Introducción. Migraciones y agricultura familiar: un vínculo perdurable. Revista de Ciencias Sociales, (28), 13-32.

Paniagua, A. (2002). Urban-rural migration, tourism entrepreneurs and rural restructuring in Spain. Tourism Geographies, (4), 349-371. Doi: https://doi. org/10.1080/14616680210158128

Pérez Winter, C. (2017). Del turismo "cultural" al "rural": un caso de la Pampa bonaerense (Argentina). Revista de Geografía, 26(2), 261-278. Doi: http://dx.doi.org/10.15446/rcdg. v26n2.59105

Prados, M. (2011). Naturbanización. Ejemplos en áreas de montaña y periurbanas. Sociedad Catalana de Geografía, (7172), 179-200.

Ratier, H. (2002). Rural, ruralidad, nueva ruralidad y contraurbanización. Un estado de la cuestión. Revista de Ciências Humanas, 31, 9-29.
Ratier, H. (2003). Estrategias regresivas en la pampa globalizada y las fronteras entre lo rural y lo urbano". En, Runa (24) (233-255). Buenos Aires: Facultad de Filosofía y Letras, UBA.

Rivera Escribano, M. (2007). La ciudad no era mi lugar. Los significados residenciales de la vuelta al campo en Navarra. Pamplona: Universidad Pública de Navarra.

Rodríguez, J., \& Busso, G. (2009). Migración interna y desarrollo en América Latina entre 1980 y 2005. Un estudio comparativo con perspectiva regional basado en siete paises. Chile: CEPAL.

Rockwell, E. (2009). Reflexiones sobre el trabajo etnográfico. En La experiencia etnográfica. Historia y cultura en los procesos educativos (pp. 41-99). Buenos Aires: Paidós.

Salinardi, J. (2006). Córdoba y Traslasierra. Integración y disgregación. Reseña histórica de la ocupación del territorio de Córdoba. Córdoba: Lerner.

Sofranko, A., \& Williams, J. (1980). Rebirth of rural America: Rural migration in the midwest. Iowa: State University.

Thoreau, H. (2013). Walden. La vida en los bosques. Buenos Aires: Andrómeda.

Tönnies, F. (2009). Comunidad y asociación. Madrid: Comares.

Trimano, L. (2014). De la ciudad al campo. Tensiones entre culturas emergentes y preexistentes. El caso de Las Calles, Traslasierra, Córdoba. (Tesis doctoral, Universidad Nacional de Córdoba, Argentina). territorias 41

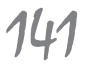


Trimano, L. (2015). Integración social y nueva ruralidad: ser ‘hippie? en el campo. Revista Antropología Social, 24, 317-348. Doi: http://dx.doi. org/10.5209/rev_RASO.2015. v24.50660

Trimano, L. (2016). Habitar, percibir y narrar el territorio. La construcción subjetiva de una tensión rural/urbana. Cuadernos de Vivienda y Urbanismo, (09), 212-231. Doi: https://doi. org/10.11144/Javeriana.cvu9-18. hpnt

Trimano, L. (2017). Paisas y gringos. Neorruralidad serrana, transformaciones relacionales e identidades emergentes. Chungara, 49(3), 461-471. Doi: http://dx.doi.org/10.4067/ S0717-73562017005000023

Trimano, L., \& de Abrantes, L. (2017). Procesos de comunicación y nuevas movilidades en pequeñas y medianas aglomeraciones argentinas. Ponencia presentada en las IV Jornadas Internacionales de Sociología de la AMS, UCM, Madrid.
Trimano, L., \& de Abrantes, L. (2018). De elegias y encanto. Pensar la gran ciudad desde afuera. Ponencia presentada en el III Congreso Internacional de Vivienda y Ciudad, FAUD, UNC, Argentina.

Turner, V. (1980). La selva de los símbolos. Madrid: Siglo XXI Editores.

Urry, J. (2007). Mobilities. Cambridge: Polity

Valles, M. (1999). Técnicas cualitativas de investigación social. Madrid: Síntesis.

van Gennep, A. (1969). The rites of passage. Chicago: The University of Chicago Press.

Zunino Singh, D., Giucci, G., \& Jirón, P. (Eds.). (2017). Términos clave para los estudios de movilidad en América Latina. Buenos Aires: Biblos.

Zusman, P., Lois, C., \& Castro, H. (Comps.). (2007). Viajes y geografias: exploraciones, turismo y migraciones en la construcción de lugares. Buenos Aires: Prometeo. 